\title{
Pre-processing data using wavelet transform and PCA based on support vector regression and gene expression programming for river flow simulation
}

\author{
Abazar Solgi ${ }^{1, *}$, Amir Pourhaghi $^{1}$, Ramin Bahmani $^{2}$ and Heidar Zarei ${ }^{3}$ \\ ${ }^{1}$ Department of Water Resources Engineering, Shahid Chamran University of Ahvaz, Ahvaz, Iran. \\ ${ }^{2}$ Department of Science and Water Engineering, Shahid Chamran University of Ahvaz, Ahvaz, Iran. \\ ${ }^{3}$ Department of Hydrology and Water Resources, Shahid Chamran University of Ahvaz, Ahvaz, Iran. \\ *Corresponding author. e-mail: A-solgi@phdstu.scu.ac.ir
}

MS received 8 July 2016; revised 28 February 2017; accepted 1 March 2017; published online 14 July 2017

An accurate estimation of flow using different models is an issue for water resource researchers. In this study, support vector regression (SVR) and gene expression programming (GEP) models in daily and monthly scale were used in order to simulate Gamasiyab River flow in Nahavand, Iran. The results showed that although the performance of models in daily scale was acceptable and the result of SVR model was a little better, their performance in the daily scale was really better than the monthly scale. Therefore, wavelet transform was used and the main signal of every input was decomposed. Then, by using principal component analysis method, important sub-signals were recognized and used as inputs for the SVR and GEP models to produce wavelet-support vector regression (WSVR) and wavelet-gene expression programming. The results showed that the performance of WSVR was better than the SVR in such a way that the combination of SVR with wavelet could improve the determination coefficient of the model up to $3 \%$ and $18 \%$ for daily and monthly scales, respectively. Totally, it can be said that the combination of wavelet with SVR is a suitable tool for the prediction of Gamasiyab River flow in both daily and monthly scales.

Keywords. Pre-processing data; flow simulation; WSVR; WGEP; Gamasiyab River.

\section{Introduction}

The increasing need for water leads humans to the planning management for controlling the use of water more and more. Not only does the prediction of river flow help us manage the exploitation of water resources, but it also helps us predict and control natural disasters like flood and drought. These issues have always been one of the water resource management challenges. Therefore, many methods have been used by researchers to achieve this goal which includes regression techniques, conceptual models, and more complex methods based on Artificial Neural Network (ANN) and NeuroFuzzy methods. The ANN has been used in many sciences and also the prediction of run-off for a long time (Hamzaçebi 2008; Wu et al. 2009; Dorum et al. 2010; Wu and Chau 2011; Asadi et al. 2013; Piotrowski and Napiorkowski 2013; Solgi 2014) and all researchers claimed that the ANN is suitable for the prediction of run-off. In this field, good searches have been done on the prediction of river flow and run-off using Adaptive Neuro Fuzzy Inference System (ANFIS) model as well (Nayak et al. 2004; Nourani et al. 2009a, b; Pramanik and Panda 2009; Talei et al. 2010; Nourani 
and Komasi 2013). In these studies, the function of ANFIS model, like ANN model, has been verified as a suitable model for predicting river flow.

However, in recent years, a lot of research has been done in order to improve the function of ANNs. One of the tools which has been used in hydrology to increase the accuracy of the prediction of river flow is combined models with a wavelet transform. With the advent of wavelet theory in the last century, using this tool in the hydrology has been an effective step to increase the accuracy of models. In this field, for predicting hydrological parameters, some searches have been done by combining the ANN with wavelet transform. For example, Nourani et al. (2009a, b) and Solgi et al. (2014a) used hybrid Wavelet-Artificial Neural Network (WANN) for predicting precipitation. Kisi (2008), Adamowski and Sun (2010) and Shoaib et al. (2014) used WANN for predicting river flow. Belayneh et al. (2014, 2016) and Danandeh Mehr et al. (2014) benefited from WANN for predicting drought. In all studies, the ability of WANN for predicting hydrological parameters has been proved. It may be said that the first studies, in the field of predicting river flow by a combination of models with the wavelet transform, was done by Nakken (1999). However, by creating new models, using the ANN has been paler.

In hydrologic problems, nevertheless, some new methods called support vector machines (SVR) have been used lately. These models are based on statistical learning theory, which is a new model in order to classify, predict data, and be used in different sciences. For instance, Kisi and Cimen (2012) used wavelet-support vector regression (WSVR) model to predict daily precipitation for two stations in Turkey. The result showed that the WSVR had a better function than the SVR (Kisi and Cimen 2012). In another study, the performance of SVM in hydrology was detected by Sujay Raghavendra and Deka (2014). In this study, the works on the use of SVM, has been presented (Sujay Raghavendra and Deka 2014). The comparison of ANFIS, ANN, and SVM was done for the prediction of river flow by He et al. (2014). The result of the comparison showed that the SVM had better performance than other models (He et al. 2014). The combination of WSVR was detected for the prediction of monthly water table fluctuation in Visakhapatnam, India. In this study,
ARIMA, SVR, ANN, and WA-SVR were compared. The results showed that WA-SVR was the best model for predicting the fluctuation of water tables (Suryanarayana et al. 2014).

In addition, gene expression programming (GEP) is a branch of evolutionary algorithms that have a high ability for simulating non-linear and dynamic processes. In this field, Kisi et al. (2011) presented a hybrid model of WGEP for predicting long- and short-term temperature. In this study, the daily and monthly temperature in Mahabad and Oromie stations were predicted and the results showed that the WGEP has a better performance (Kisi et al. 2011). The comparison of GEP with ANFIS for short-term prediction of groundwater levels was done by Shiri and Kişi (2011). The results proved that both the models can be accurate models for predicting groundwater levels, but the GEP has easier formula structures (Shiri and Kişi 2011).

Modeling daily reference evapotranspiration was done using the GEP in Basque Country (the north of Spain) by Shiri et al. (2012) from 1999 to 2003. The results of GEP were compared with the ANFIS, Priestley-Taylor, and Hargreaves-Samani. The results indicated that the GEP was the best model and after that the ANFIS was the best (Shiri et al. 2012). Shoaib et al. (2015) predicted runoff using the WGEP for four basins from different places of the world which had precipitation and run-off data. Then, mother wavelet performance was detected. The results showed that the WGEP with Dmey wavelet model had better performance than the GEP (Shoaib et al. 2015). Karimi et al. (2015) evaluated the long- and short-term flow prediction of Filyos River in Turkey using the WGEP. The result showed that hybrid model had a better performance than the GEP. They also used ARMA, ANN, and ANFIS for comparing. They found that hybrid model was the best model (Karimi et al. 2015).

Regarding the importance of short-term prediction in water resource engineering, non-linear feature, and instability in time series of daily and monthly flow, using a tool with suitable accuracy is one of the topics which have always been considered by researchers. Therefore, in this study, for achieving this aim, it has been tried to use the wavelet transform tool the PCA method, which has shown a good ability in hydrology, in combination with the GEP and SVM. Moreover, in comparison with simple the GEP and SVM, the effect 
of wavelet transform was detected for improving and predicting the flow of Gamasiyab River in Nahavand because the river is an important source for drinking and farming water in Nahavand city.

\section{Materials and methods}

\subsection{Study area}

Karstic Springs is located within $20 \mathrm{~km}$ to the southwest of Nahavand, the source of Gamasiyab River. This river is a major tributary of Karkheh River which has about $200 \mathrm{~km}$ length and 20-50 m width and with the depth of $0.5-2 \mathrm{~m}$. Varayeneh,

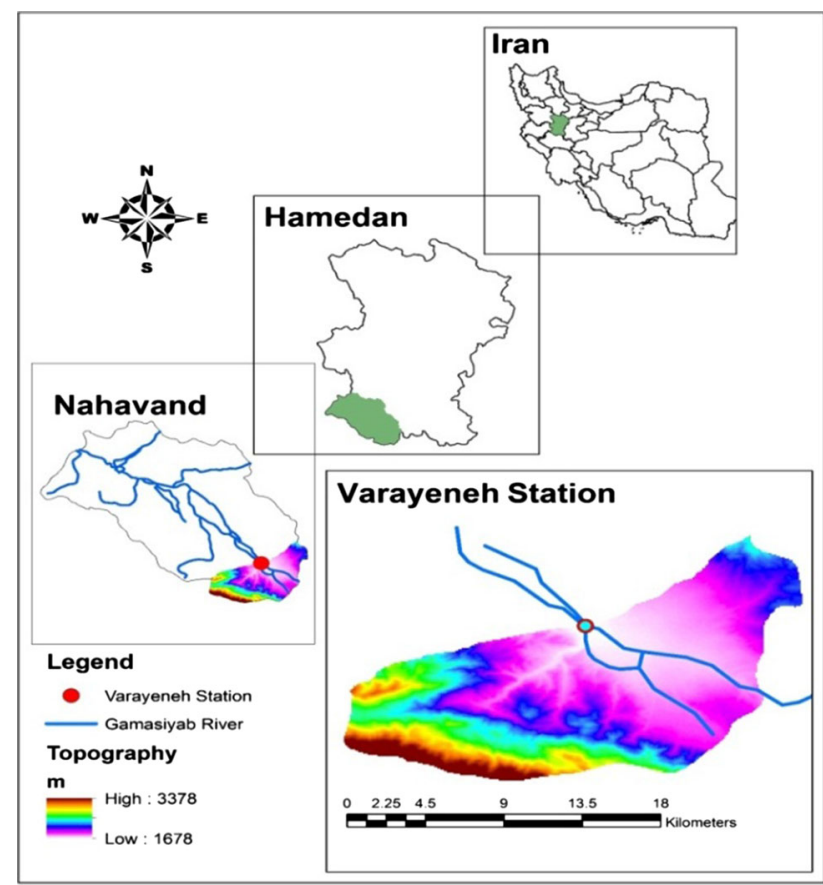

Figure 1. Location of Varayeneh station and Gamasiyab River in Nahavand, Hamedan, Iran. including hydrometric, pluviometry, and evaporimeter stations, is its station. This station is located at $48^{\circ} 24^{\prime} 15^{\prime \prime} \mathrm{E}$ and $34^{\circ} 04^{\prime} 32^{\prime \prime} \mathrm{N}$. This station is 1795 meters above the sea level. In this study, the precipitation, temperature, evaporation, and flow data were used from 1969 to 2011. Figure 1 and table 1 show the location of the station and the place with its parameters.

\subsection{Preparing data}

Because inputting raw data decreases the accuracy and speed of model, the standardization method (converting data to the numbers between 0 and 1) is used. By the standardization, each integer converted to the number between 0 and 1 (Riad et al. 2004). According to Solgi et al. (2014b) suggestion, the below equation was used for normalizing.

$$
y=0.5+\left(0.5 \times\left(\frac{x-\bar{x}}{x_{\max }-x_{\min }}\right)\right)
$$

where $x$ is data, $\bar{x}$ is the average of data, $x_{\max }$ is the maximum value of the data, $x_{\min }$ is the minimum value of data, and $y$ is standardized data. After standardizing, $75 \%$ of the data was used for training data and $25 \%$ considered for simulating data.

\subsection{Support vector machines (SVM)}

SVM is a classifier, part of kernel methods, for training machine. This type of learning system is used for classifying, estimating, and fitting function data in such a way that minimum error is produced in classifications and fitness functions. In these days, support vector machines have been considered to a great extent; the use of SVM has had

Table 1. Some climatic variables of Varayeneh station.

\begin{tabular}{|c|c|c|c|c|c|c|c|}
\hline Time scale & $\begin{array}{l}\text { Climatic } \\
\text { variable }\end{array}$ & $\begin{array}{c}\text { Unit of } \\
\text { measurement }\end{array}$ & Average & Maximum & Minimum & $\begin{array}{l}\text { Standard } \\
\text { deviation }\end{array}$ & $\begin{array}{l}\text { Coefficient } \\
\text { of variation }\end{array}$ \\
\hline \multirow{4}{*}{ Daily } & Flow & $\mathrm{m}^{3} / \mathrm{s}$ & 3.78 & 22.86 & 0.67 & 2.4 & 0.64 \\
\hline & Precipitation & $\mathrm{mm}$ & 1.43 & 96 & 0.0 & 5.3 & 3.69 \\
\hline & Temperature & ${ }^{\circ} \mathrm{C}$ & 11.09 & 46 & -34 & 9.6 & 0.87 \\
\hline & Evaporation & $\mathrm{mm}$ & 4.94 & 24.5 & 0.0 & 4.4 & 0.88 \\
\hline \multirow{4}{*}{ Monthly } & Flow & $\mathrm{m}^{3} / \mathrm{s}$ & 3.76 & 12.93 & 0.97 & 2.3 & 0.60 \\
\hline & Precipitation & $\mathrm{mm}$ & 43.8 & 266 & 0.0 & 48.9 & 1.12 \\
\hline & Temperature & ${ }^{\circ} \mathrm{C}$ & 10 & 26.5 & -9.10 & 9.2 & 0.92 \\
\hline & Evaporation & $\mathrm{mm}$ & 150.2 & 409.9 & 0.0 & 127.4 & 0.85 \\
\hline
\end{tabular}


good results in works like recognizing handwriting, faces and so forth.

\subsubsection{Non-linear SVM}

In this case, the kernel functions are used. The kernel functions can be written as:

$$
\begin{aligned}
& k(x, y)=(x \cdot y+1)^{d} \quad d=2,3, \ldots \\
& k(x, y)=\exp \left(-\frac{\|x-y\|^{2}}{2 \sigma^{2}}\right) \\
& k(x, y)=\tanh (x \cdot y+\theta) \\
& k(x, y)=(x \cdot y) .
\end{aligned}
$$

These kernels are the polynomial kernel, RBF kernel, sigmoid kernel and linear kernel respectively (Sujay Raghavendra and Deka 2014).

The RBF kernel has only one gamma parameter which displays $g$. For this parameter, the default value $1 / k$ ( $k$ is the number of features) is used. On the other hand, no value is entered for gamma and also the value of $1 / k^{2}$ and 1 is tested. In the sigmoidal kernel, regarding problems arise for the convergence of answers, just the default values, including zero and $1 / k$ gamma, are used and it means the kernel does not have a parameter.

The linear core does not have any parameter, so there is just one status. The polynomial core has two parameters. The first parameter, called $d$, shows the degree of the polynomial and the problem can be solved with a value of $1,2,3$, and 4 . For the second parameter, which is an accumulative fixed number called $r$, there are three status of 0 , 1 , and -1 . For more information in this field, refer Cortes and Vapnik (1995) and Sujay Raghavendra and Deka (2014).

\subsection{Gene expression programming (GEP)}

The GEP, which is developed shape of genetic programming, was presented by Ferreira (2001). This method is a part of circulating algorithm methods. This method has been developed following the intelligent evolution models based on the evolution theory of Darwin (Danandeh Mehr and Majdzadeh Tabatabai 2010).

In this method, linear and simple chromosomes with fixed length, similar to those which are used in the genetic algorithm, and branch structures with different sizes and shapes, similar to the decomposition tree in genetic programming, are combined with each other. The first step in the algorithm of model is producing primary population from solutions. This work can be done by accidental process or considering input information about problems. Then, chromosomes are presented as a tree expression and are evaluated by a fitness function. If a suitable solution is obtained or generations achieve to a given number, the evolution will be stopped and the best solution will be presented. If the stop condition is not found, the elite choice is done and remind solutions are assigned to electing process. The process is done for several generations and by going generation to forward, the quality of the population has relatively improved (Ferreira 2006).

In GEP, different operators such as jumps and combinations are used. The goal of jump operator is random improvements in the special chromosome. The feature of the operator is that for avoiding producing disable factors, in terms of rules, some operations without malfunction are run. In this model, the single-point, two-point, and gene combination are used. Because two-point combination is able to turn on-and-off non-coded areas in chromosomes more, it is more favourable. Another operator used is called transposition. In this method, different phenomena are modeled using a group of functions and terminals. The group of a function includes account, trigonometric, and defined functions with an operator which believes that it is suitable for interpreting the model. The group of terminals includes fixed values and independent variables (Ferreira 2001).

\subsection{Wavelet transform}

Every variable quantity, which can be measured in a time or place is called signal. For analyzing signals, mathematical converters are used to obtain information which is not available from raw signals. The wavelet transform is one of the efficient mathematical converters for processing signals. The most important advantage of the wavelet transform is extracting the information of time and place from variable signals properly. Wavelet function $\psi(t)$ is called Mother Wavelet if has three features: (a) limited number of fluctuations, (b) returning to zero very fast in both negative and positive of its domain, and (c) the zero average.

Wavelet function $\psi(t)$ in mathematical form is defined as (Mallat 1998):

$$
\int_{-\infty}^{+\infty} \psi(t) d(t)=0
$$


$\psi_{(a, b)}(t)$ can be calculated by a lag time and changes in Mother Wavelet scale as (Mallat 1998):

$$
\begin{aligned}
\psi_{(a, b)}(t)= & |a|^{-0.5} \psi\left(\frac{t-b}{a}\right), \\
& a \in R, b \in R, a \neq 0 .
\end{aligned}
$$

The wavelet transform is divided into continuous and discrete classes. In practical applications, hydrologists do not usually have access to continuous signals. The divided wavelet transform benefits filter banks for renovating the level of multi-level time-frequency separation. One of the most important and basic notes in selecting mother wavelets is the nature of phenomenon and the type of its time series (Solgi 2014). In this study, Haar, Coifl, Sym3, Db4, and Db2 were selected. Figure 2 shows the wavelet functions.

By using these functions, time series of precipitation, temperature, evaporation, and river flow in several steps, until removing the fluctuation of series, were decomposed to several sub-series and then used as inputs for the model. If more steps are used for the selection process for decomposing, the signal as many as high and low frequencies pass is decomposed and the accuracy increases, but after a step, the values of frequencies are approximately fixed.
For more information in this field, refer FoufoulaGeorgiou and Kumar (1994) and Mallat (1998).

\subsection{Different structures for modeling}

In this study, because in addition to different parameters (precipitation, temperature, and evaporation), the flow sequence with lag times for prediction of river flow is considered as well. Different combinations based on table 2 were used for the SVR.

In this study, GeneXpro Tools(v5) was used for the GEP. In this method, selecting primary populations, which are input patterns, are so important. Therefore, different combinations based on table 2 for GEP were used.

\subsection{Principal component analysis (PCA)}

Principal component analysis (PCA) is the type of statistical analysis which selects the lesser factor named the main factor among the initial factors so that the number of trivial information is deleted. Whenever, the testing factor of Kaiser-MeyerOlkin (KMO) related to this method is $<0.5$, the data are not appropriate for PCA and if the value of KMO is between 0.5 and 0.69 , we should be careful in the factor analysis, but if the value is $>0.7$, the correlation existing between the data
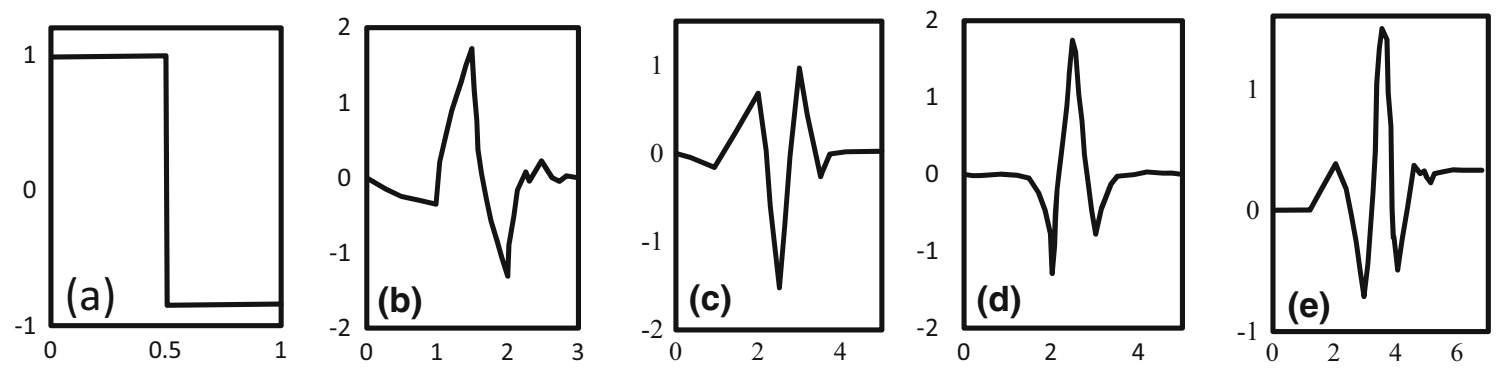

Figure 2. (a) Haar wavelet, (b) Db2 wavelet, (c) Sym3 wavelet, (d) Coif1 wavelet and (e) Db4 wavelet.

Table 2. Combination details of GEP and SVR models.

\begin{tabular}{llc}
\hline Combination & \multicolumn{1}{c}{ Inputs } & Output \\
\hline 1 & $Q_{t-1}, Q_{t}$ & $\boldsymbol{Q}_{\boldsymbol{t}+\mathbf{1}}$ \\
2 & $Q_{t}, P_{t}$ & $\boldsymbol{Q}_{\boldsymbol{t}+\mathbf{1}}$ \\
3 & $P_{t-1}, P_{t}, Q_{t-1}, Q_{t}$ & $\boldsymbol{Q}_{\boldsymbol{t}+\mathbf{1}}$ \\
4 & $P_{t}, Q_{t}, E_{t}, T_{t}$ & $\boldsymbol{Q}_{\boldsymbol{t}+\mathbf{1}}$ \\
5 & $P_{t-1}, P_{t}, Q_{t-1}, Q_{t}, E_{t-1}, E_{t}, T_{t-1}, T_{t}$ & $\boldsymbol{Q}_{\boldsymbol{t}+\mathbf{1}}$ \\
6 & $P_{t-2}, P_{t-1}, P_{t}, Q_{t-2}, Q_{t-1}, Q_{t}$, & $\boldsymbol{Q}_{\boldsymbol{t + 1}}$ \\
& $E_{t-2}, E_{t-1}, E_{t}, T_{t}, T_{t-1}, T_{t}$ &
\end{tabular}

Note. $Q_{t}, P_{t}, T_{t}, E_{t}$ are flow, precipitation, temperature and evaporation, respectively and $Q_{t-2}, Q_{t-1}, P_{t-2}, P_{t-1}, T_{t-2}, T_{t-1}$, $E_{t-2}, E_{t-1}$ are flow, precipitation, temperature and evaporation, respectively in the previous time series and $Q_{t+1}$ is flow in the next period. 


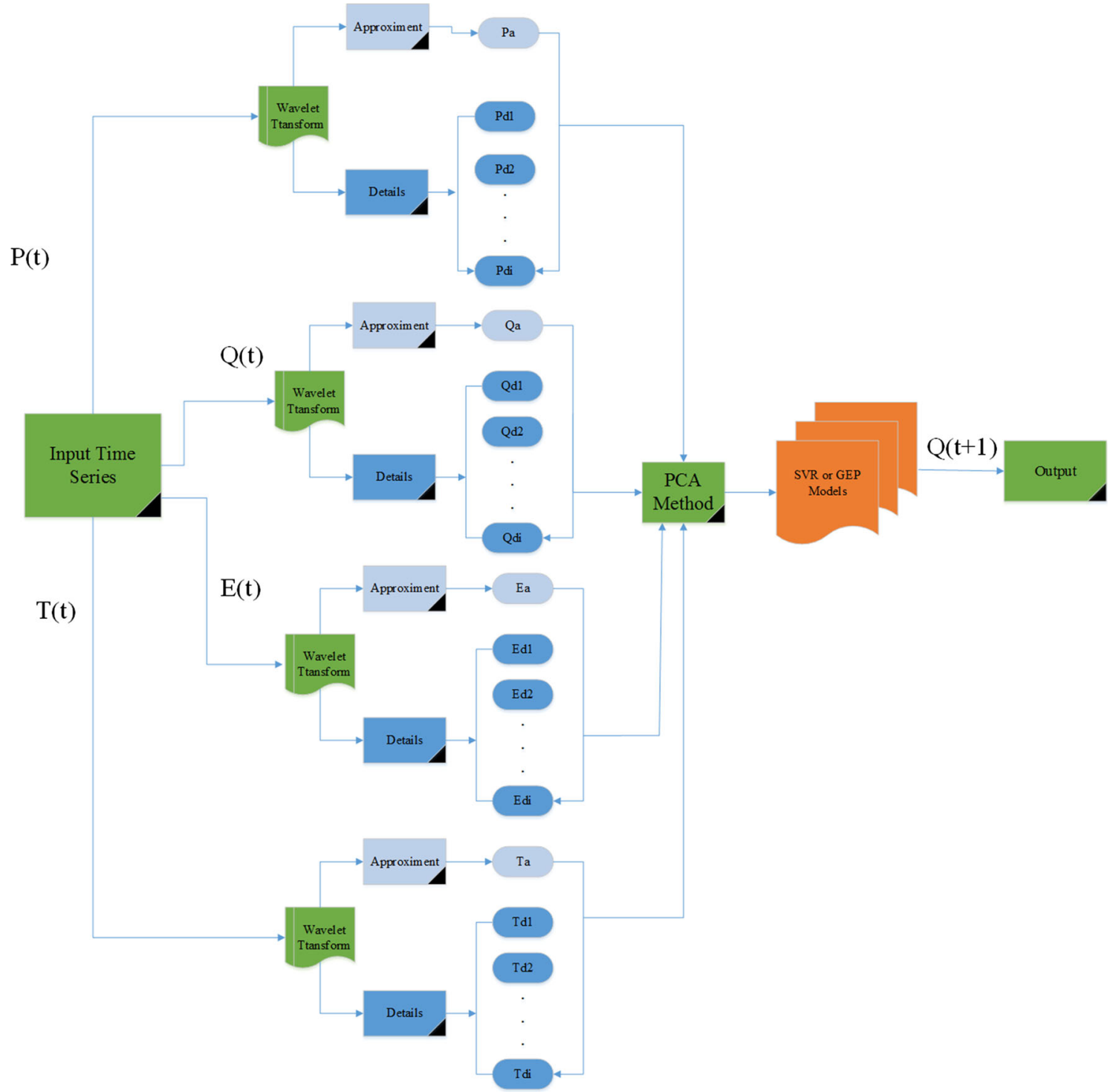

Figure 3. Schematic diagram of the WGEP and WSVR models.

Table 3. The best structure in the SVR combinations.

\begin{tabular}{|c|c|c|c|c|c|c|c|c|c|c|}
\hline \multirow[b]{3}{*}{ Combination } & \multirow[b]{3}{*}{ Time scale } & \multicolumn{5}{|c|}{ Model parameters } & \multirow{2}{*}{\multicolumn{2}{|c|}{$R^{2}$}} & \multirow{2}{*}{\multicolumn{2}{|c|}{ RMSE }} \\
\hline & & & & & & Polynomial & & & & \\
\hline & & Kernel & Gam & $\operatorname{Sin} 2$ & B & degree & Train & Test & Train & Test \\
\hline \multirow[t]{2}{*}{1} & Daily & Lin & 18.09 & - & 0.0218 & - & 0.94 & 0.92 & 0.0128 & 0.0133 \\
\hline & Monthly & $\mathrm{RBF}$ & 0.025 & 3.045 & 0.001 & - & 0.72 & 0.54 & 0.0530 & 0.0483 \\
\hline \multirow[t]{2}{*}{2} & Daily & $\mathrm{RBF}$ & 4.680 & 456.6 & 1.876 & - & 0.96 & 0.91 & 0.0120 & 0.0171 \\
\hline & Monthly & Poly & 5.565 & 1210 & 3.786 & 3 & 0.62 & 0.54 & 0.0552 & 0.0591 \\
\hline \multirow[t]{2}{*}{3} & Daily & $\mathrm{RBF}$ & 0.036 & 233.5 & -0.032 & - & 0.94 & 0.93 & 0.0129 & 0.0126 \\
\hline & Monthly & Lin & 1.680 & - & -0.098 & - & 0.73 & 0.63 & 0.0499 & 0.0490 \\
\hline \multirow[t]{2}{*}{4} & Daily & Poly & 0.001 & 0.532 & 2.987 & 4 & 0.95 & 0.94 & 0.0122 & 0.0122 \\
\hline & Monthly & $\mathrm{RBF}$ & 25.87 & 34.27 & 1.543 & - & 0.73 & 0.64 & 0.0522 & 0.0449 \\
\hline \multirow[t]{2}{*}{5} & Daily & $\mathrm{RBF}$ & 0.191 & 125.1 & -0.045 & - & 0.95 & 0.94 & 0.0127 & 0.0109 \\
\hline & Monthly & $\mathrm{RBF}$ & 0.092 & 2876 & 0.809 & - & 0.88 & 0.75 & 0.0339 & 0.0413 \\
\hline \multirow[t]{2}{*}{6} & Daily & $\mathrm{RBF}$ & 3.011 & 0.321 & 0.905 & - & 0.95 & 0.93 & 0.0130 & 0.0124 \\
\hline & Monthly & Lin & 5.843 & - & 4.108 & - & 0.90 & 0.74 & 0.0256 & 0.0422 \\
\hline
\end{tabular}


Table 4. The best structure in GEP combinations.

\begin{tabular}{|c|c|c|c|c|c|}
\hline \multirow[b]{2}{*}{ Combination } & \multirow[b]{2}{*}{ Time scale } & \multicolumn{2}{|c|}{$R^{2}$} & \multicolumn{2}{|c|}{ RMSE } \\
\hline & & Train & Test & Train & Test \\
\hline \multirow{2}{*}{1} & Daily & 0.94 & 0.92 & 0.0134 & 0.0130 \\
\hline & Monthly & 0.71 & 0.51 & 0.0527 & 0.0550 \\
\hline \multirow{2}{*}{2} & Daily & 0.94 & 0.92 & 0.0140 & 0.0132 \\
\hline & Monthly & 0.71 & 0.58 & 0.0526 & 0.0502 \\
\hline \multirow{2}{*}{3} & Daily & 0.95 & 0.92 & 0.0130 & 0.0126 \\
\hline & Monthly & 0.73 & 0.57 & 0.0512 & 0.0542 \\
\hline \multirow{2}{*}{4} & Daily & 0.95 & 0.92 & 0.0130 & 0.0127 \\
\hline & Monthly & 0.72 & 0.56 & 0.0513 & 0.0533 \\
\hline \multirow{2}{*}{5} & Daily & 0.95 & 0.92 & 0.0129 & 0.0125 \\
\hline & Monthly & 0.80 & 0.64 & 0.0433 & 0.0503 \\
\hline \multirow{2}{*}{6} & Daily & 0.94 & 0.91 & 0.0133 & 0.0135 \\
\hline & Monthly & 0.75 & 0.59 & 0.0494 & 0.0537 \\
\hline
\end{tabular}

Table 5. The value of the test statistic in PCA method.

\begin{tabular}{lcc}
\hline Kaiser-Meyer-Olkin measure of sampling adequacy & 0.607 \\
\hline Bartlett's test of sphericity & Approx. Chi-Square & 58878.050 \\
& Df & 780 \\
& Sig. & 0.000 \\
\hline
\end{tabular}

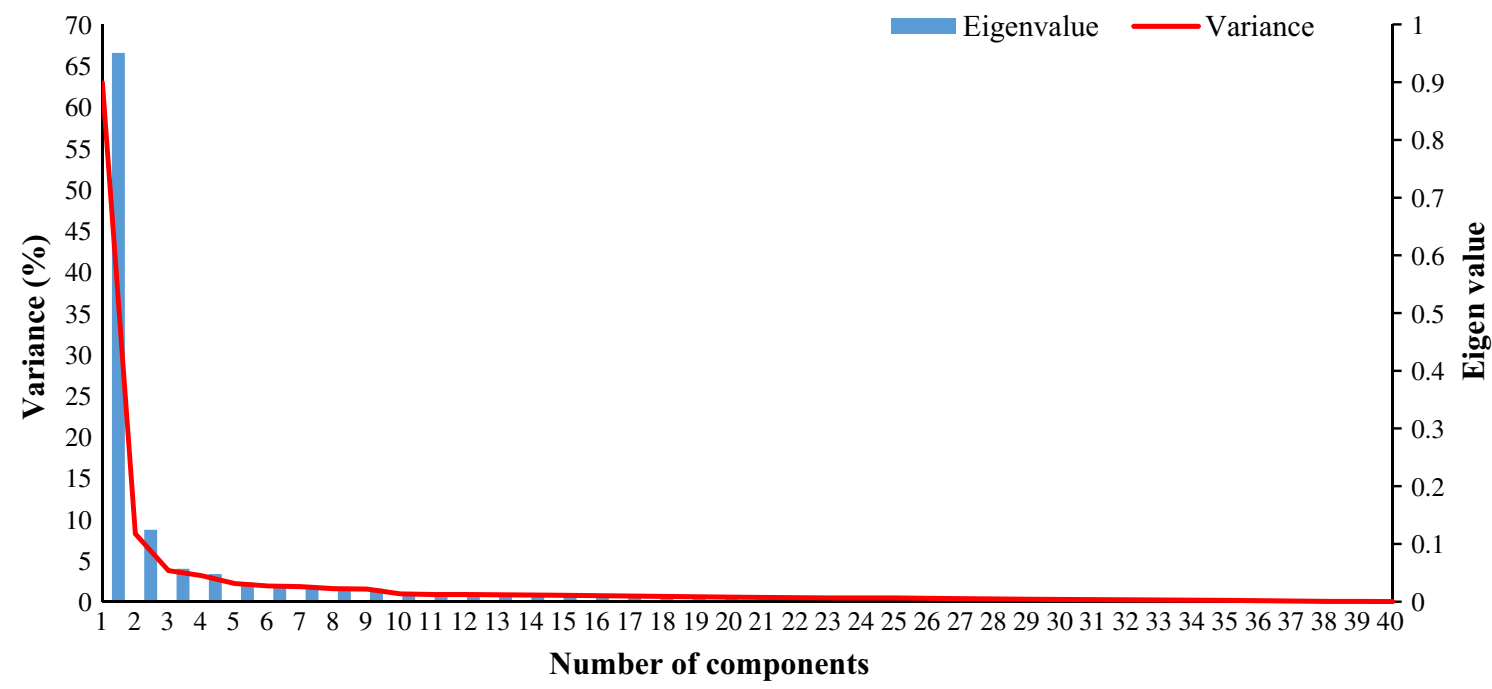

Figure 4. Scree plot of eigenvalues vs. components along with percentage variances vs. components (daily period).

are appropriate for analysis (Hutcheson and Nick 1999). By this method, some combinations of $P$ from primary variables of $x_{1}, x_{2}, \ldots, x_{p}$, for producing the maximum independent $P$ factor like $P C_{1}, P C_{2}, \ldots, P C_{p}$ are produced (Johnson and Wichern 1982).

Each principal component can be presented by the sequences in equation (5).

$$
\begin{aligned}
& P C_{1}=w_{11} x_{1}+w_{12} x_{2}+\ldots+w_{1 p} x_{p} \\
& P C_{2}=w_{21} x_{1}+w_{22} x_{2}+\ldots+w_{2 p} x_{p} \\
& \cdots \\
& P C_{p}=w_{p 1} x_{1}+w_{p 2} x_{2}+\ldots+w_{p p} x_{p}
\end{aligned}
$$

where $P C_{1}$ is the intended component, $w_{i j}$ is the coefficient of the primary variables and $x_{i}$ is the primary variable. 


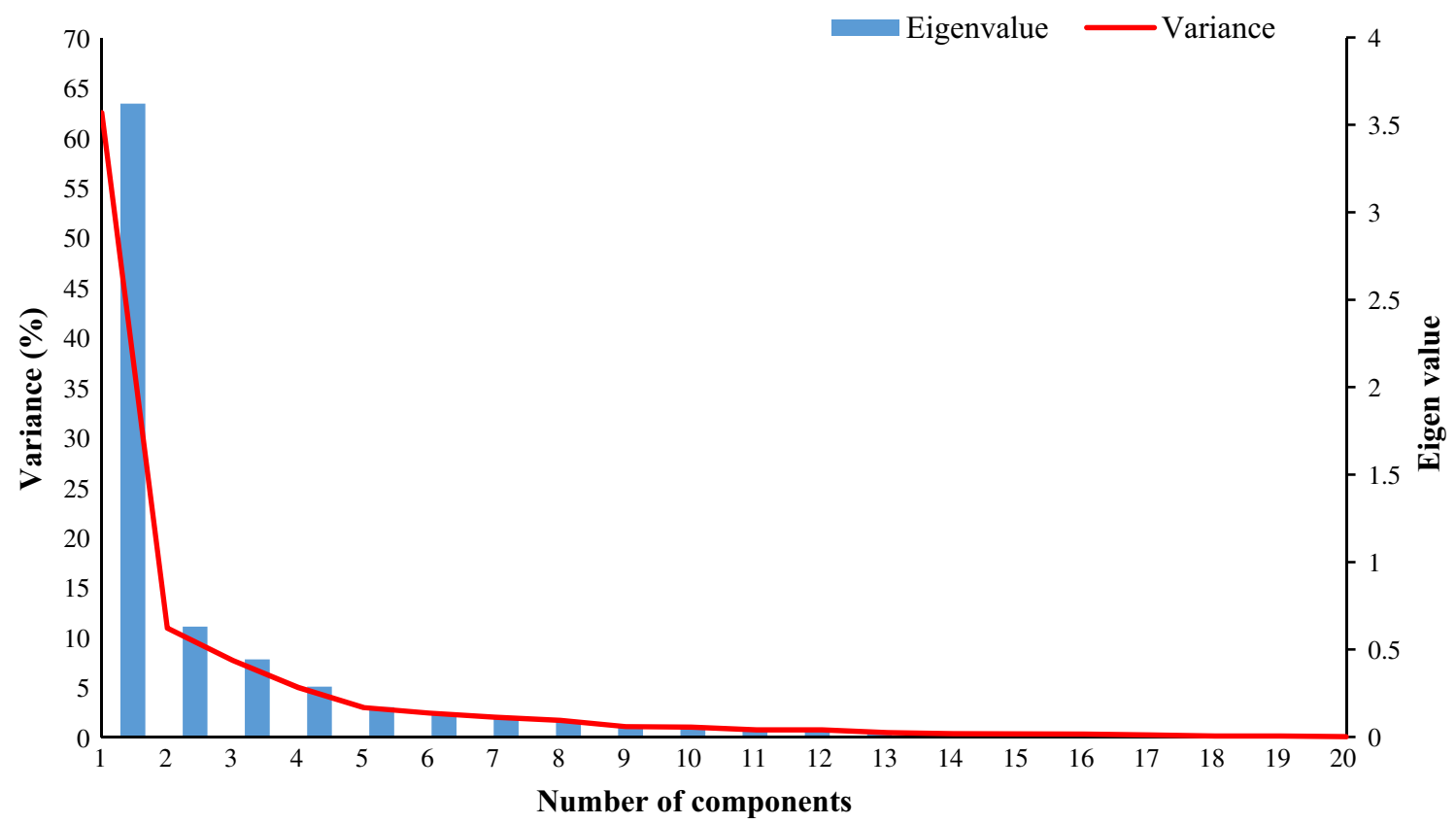

Figure 5. Scree plot of eigenvalues vs. components along with percentage variances vs. components (monthly period).

Table 6. Result of the WSVR daily with different mother wavelets and decomposition levels.

\begin{tabular}{|c|c|c|c|c|c|c|c|c|c|c|}
\hline \multirow{2}{*}{$\begin{array}{l}\text { Mother } \\
\text { wavelet type }\end{array}$} & \multirow[b]{2}{*}{ Level } & \multicolumn{5}{|c|}{ Model parameters } & \multicolumn{2}{|c|}{$R^{2}$} & \multicolumn{2}{|c|}{ RMSE } \\
\hline & & Kernel & Gamma & $\operatorname{Sin} 2$ & B & P-degree & Train & Test & Train & Test \\
\hline Coif1 & 5 & Lin & 0.643 & - & 0.0001 & - & 0.97 & 0.96 & 0.0076 & 0.0084 \\
\hline Coif1 & 6 & $\mathrm{RBF}$ & 0.029 & 1876 & -0.026 & - & 0.98 & 0.96 & 0.0072 & 0.0085 \\
\hline Coif1 & 7 & $\mathrm{RBF}$ & 0.270 & 2.809 & 0.0353 & - & 0.97 & 0.96 & 0.0077 & 0.0084 \\
\hline Coif1 & 8 & Poly & 0.005 & 2.721 & -0.564 & 3 & 0.98 & 0.96 & 0.0074 & 0.0084 \\
\hline Coif1 & 9 & $\mathrm{RBF}$ & 8.886 & 233.8 & -0.001 & - & 0.98 & 0.96 & 0.0078 & 0.0085 \\
\hline Sym3 & 5 & Lin & 0.040 & - & 0.0454 & - & 0.98 & 0.96 & 0.0070 & 0.0082 \\
\hline Sym3 & 6 & Lin & 0.887 & - & 0.6506 & - & 0.98 & 0.96 & 0.0075 & 0.0083 \\
\hline Sym3 & 7 & $\mathrm{RBF}$ & 0.034 & 78.75 & 0.5060 & - & 0.98 & 0.96 & 0.0076 & 0.0083 \\
\hline Sym3 & 8 & $\mathrm{RBF}$ & 0.456 & 8765 & 0.5347 & - & 0.98 & 0.96 & 0.0073 & 0.0084 \\
\hline Sym3 & 9 & $\mathrm{RBF}$ & 0.390 & 7.786 & 0.1347 & 3 & 0.98 & 0.96 & 0.0076 & 0.0085 \\
\hline Haar & 5 & $\mathrm{RBF}$ & 109.0 & 25.67 & -6.462 & - & 0.98 & 0.95 & 0.0071 & 0.0090 \\
\hline Haar & 6 & $\mathrm{RBF}$ & 78.90 & 61.77 & -0.878 & - & 0.98 & 0.95 & 0.0072 & 0.0089 \\
\hline Haar & 7 & Lin & 0.989 & - & 0.2118 & - & 0.98 & 0.96 & 0.0075 & 0.0083 \\
\hline Haar & 8 & $\mathrm{RBF}$ & 0.123 & 10.08 & 0.1465 & - & 0.98 & 0.96 & 0.0076 & 0.0084 \\
\hline Haar & 9 & $\mathrm{RBF}$ & 0.143 & 344.2 & 0.5662 & - & 0.98 & 0.95 & 0.0076 & 0.0086 \\
\hline Db2 & 5 & Lin & 0.234 & - & 0.0008 & - & 0.98 & 0.96 & 0.0070 & 0.0080 \\
\hline Db2 & 6 & $\mathrm{RBF}$ & 0.765 & 272.3 & 0.0247 & - & 0.98 & 0.96 & 0.0071 & 0.0081 \\
\hline Db2 & 7 & $\mathrm{RBF}$ & 0.020 & 138.0 & -0.513 & - & 0.98 & 0.96 & 0.0073 & 0.0083 \\
\hline Db2 & 8 & Poly & 0.565 & 1267 & -8.075 & 3 & 0.98 & 0.96 & 0.0073 & 0.0083 \\
\hline Db2 & 9 & $\mathrm{RBF}$ & 0.056 & 0.989 & 3.7203 & - & 0.98 & 0.96 & 0.0074 & 0.0084 \\
\hline Db4 & 5 & RBF & 0.278 & 651.4 & -0.098 & - & 0.99 & 0.97 & 0.0069 & 0.0075 \\
\hline Db4 & 6 & $\mathrm{RBF}$ & 1.458 & 0.653 & 9.7868 & - & 0.98 & 0.96 & 0.0071 & 0.0078 \\
\hline Db4 & 7 & $\mathrm{RBF}$ & 345.6 & 3.785 & 0.0385 & - & 0.98 & 0.96 & 0.0073 & 0.0079 \\
\hline Db4 & 8 & Poly & 0.216 & 2.067 & 1.0898 & 3 & 0.98 & 0.95 & 0.0073 & 0.0083 \\
\hline $\mathrm{Db} 4$ & 9 & Poly & 0.289 & 0.565 & 0.2341 & 4 & 0.98 & 0.95 & 0.0074 & 0.0085 \\
\hline
\end{tabular}


Table 7. Result of the WSVR monthly with different mother wavelets and decomposition levels.

\begin{tabular}{|c|c|c|c|c|c|c|c|c|c|c|}
\hline \multirow{2}{*}{$\begin{array}{l}\text { Mother } \\
\text { wavelet type }\end{array}$} & \multirow[b]{2}{*}{ Level } & \multicolumn{5}{|c|}{ Model parameters } & \multicolumn{2}{|c|}{$R^{2}$} & \multicolumn{2}{|c|}{ RMSE } \\
\hline & & Kernel & Gamma & $\operatorname{Sin} 2$ & $\mathrm{~B}$ & $\mathrm{P}$-degree & Train & Test & Train & Test \\
\hline Coif1 & 1 & $\mathrm{RBF}$ & 0.0039 & 366.09 & 0.2175 & - & 0.93 & 0.79 & 0.0258 & 0.0381 \\
\hline Coif1 & 2 & $\mathrm{RBF}$ & 344.07 & 12.987 & 0.0001 & - & 0.96 & 0.85 & 0.0194 & 0.0301 \\
\hline Coif1 & 3 & Poly & 5432 & 0.809 & -0.531 & 3 & 0.96 & 0.84 & 0.0209 & 0.0321 \\
\hline Coif1 & 4 & Poly & 391.05 & 2.721 & -1209 & 4 & 0.94 & 0.82 & 0.0250 & 0.0332 \\
\hline Sym3 & 1 & $\mathrm{RBF}$ & 6543 & 101.7 & 0.0224 & - & 0.90 & 0.81 & 0.0309 & 0.0360 \\
\hline Sym3 & 2 & Lin & 0.001 & - & 0.0400 & - & 0.93 & 0.84 & 0.0260 & 0.0332 \\
\hline Sym3 & 3 & Lin & 700.87 & - & -8.016 & - & 0.95 & 0.79 & 0.0214 & 0.0395 \\
\hline Sym3 & 4 & $\mathrm{RBF}$ & 2.734 & 783.01 & 3.7034 & - & 0.92 & 0.77 & 0.0281 & 0.0424 \\
\hline Haar & 1 & Poly & 0.0326 & 11.65 & 1.9930 & 3 & 0.90 & 0.69 & 0.0304 & 0.0425 \\
\hline Haar & 2 & $\mathrm{RBF}$ & 9654 & 7.786 & 9.7501 & - & 0.92 & 0.76 & 0.0274 & 0.0374 \\
\hline Haar & 3 & $\mathrm{RBF}$ & 1.980 & 7543 & 0.0385 & - & 0.96 & 0.67 & 0.0202 & 0.0435 \\
\hline Haar & 4 & $\mathrm{RBF}$ & 0.9760 & 72.54 & -0.264 & - & 0.93 & 0.66 & 0.0264 & 0.0489 \\
\hline Db2 & 1 & $\mathrm{RBF}$ & 0.834 & 423.1 & 0.0038 & - & 0.87 & 0.72 & 0.0357 & 0.0421 \\
\hline Db2 & 2 & Lin & 151.94 & - & -0.002 & - & 0.91 & 0.76 & 0.0299 & 0.0396 \\
\hline Db2 & 3 & $\mathrm{RBF}$ & 2345 & 17.256 & 1.0872 & - & 0.94 & 0.73 & 0.0242 & 0.0408 \\
\hline Db2 & 4 & Lin & 7754 & - & 0.0258 & - & 0.90 & 0.72 & 0.0309 & 0.0411 \\
\hline Db4 & 1 & Poly & 0.005 & 12.005 & -1.525 & 3 & 0.92 & 0.89 & 0.0287 & 0.0266 \\
\hline Db4 & 2 & RBF & 0.0164 & 20.709 & -0.004 & - & 0.96 & 0.92 & 0.0200 & 0.0219 \\
\hline Db4 & 3 & $\mathrm{RBF}$ & 0.162 & 5640 & -0.267 & - & 0.96 & 0.91 & 0.0191 & 0.0227 \\
\hline Db4 & 4 & Poly & 1.9565 & 3.607 & -5.213 & 3 & 0.95 & 0.86 & 0.0216 & 0.0299 \\
\hline
\end{tabular}

The $w_{i j}$ is estimated in a way that the first component considered the maximum variance of the data and the second component predict the maximum variance that is not considered by the first component and this approach continues until the last component cover all intended variances.

$$
\begin{gathered}
w_{i 1}^{2}+w_{i 2}^{2}+\ldots+w_{i p}^{2}=1, \quad i=1, \ldots, p \\
w_{i 1} w_{j 1}+w_{i 2} w_{j 2}+\ldots+w_{i p} w_{j p}=0 \\
\text { for all } i \neq j .
\end{gathered}
$$

To perform the PCA, following steps are carried out.

- Standardization of the input variables: in this step, the input data are standardized in the way that they have a mean of zero and a standard deviation of 1 .

$Z$ is the matrix which includes standardized values of parameters and obtained with equation (8) (Caliendo and Parisi 2005).

$$
\begin{aligned}
\mathrm{Z}_{i j}= & \left(\frac{x_{i j}-\overline{x_{j}}}{s_{j}}\right) \\
& \text { for } i=1,2, \ldots, n \text { and } j=1,2, \ldots, q .
\end{aligned}
$$

In this equation, $\overline{x_{j}}$ is the mean data and $s_{j}$ is the standard deviation.

- The calculation of KMO: the used KMO index is within the range of 0 and 1.

This index is obtained by equation (9) that in this equation, $r_{i j}$ is the correlation coefficient between the variables $i$ and $j$, and $a_{i j}$ is the partial correlation coefficient between them (Hutcheson and Nick 1999).

$$
\mathrm{KMO}=\frac{\sum \sum r_{i j}^{2}}{\sum \sum r_{i j}^{2}+\sum \sum a_{i j}^{2}} .
$$

- Calculation of correlation matrix (covariance) for the primary variables:

This matrix shows the correlation value between each used primary variable.

The value of each matrix elements of $a_{i j}$ represent the correlation between variables $i$ and $j$ which is obtained from equation (10) (Caliendo and Parisi 2005).

$$
R=\frac{1}{n} \dot{Z} Z
$$

- The calculation of corresponding eigenvalues and eigenvectors from the correlation matrix (Caliendo and Parisi 2005). 

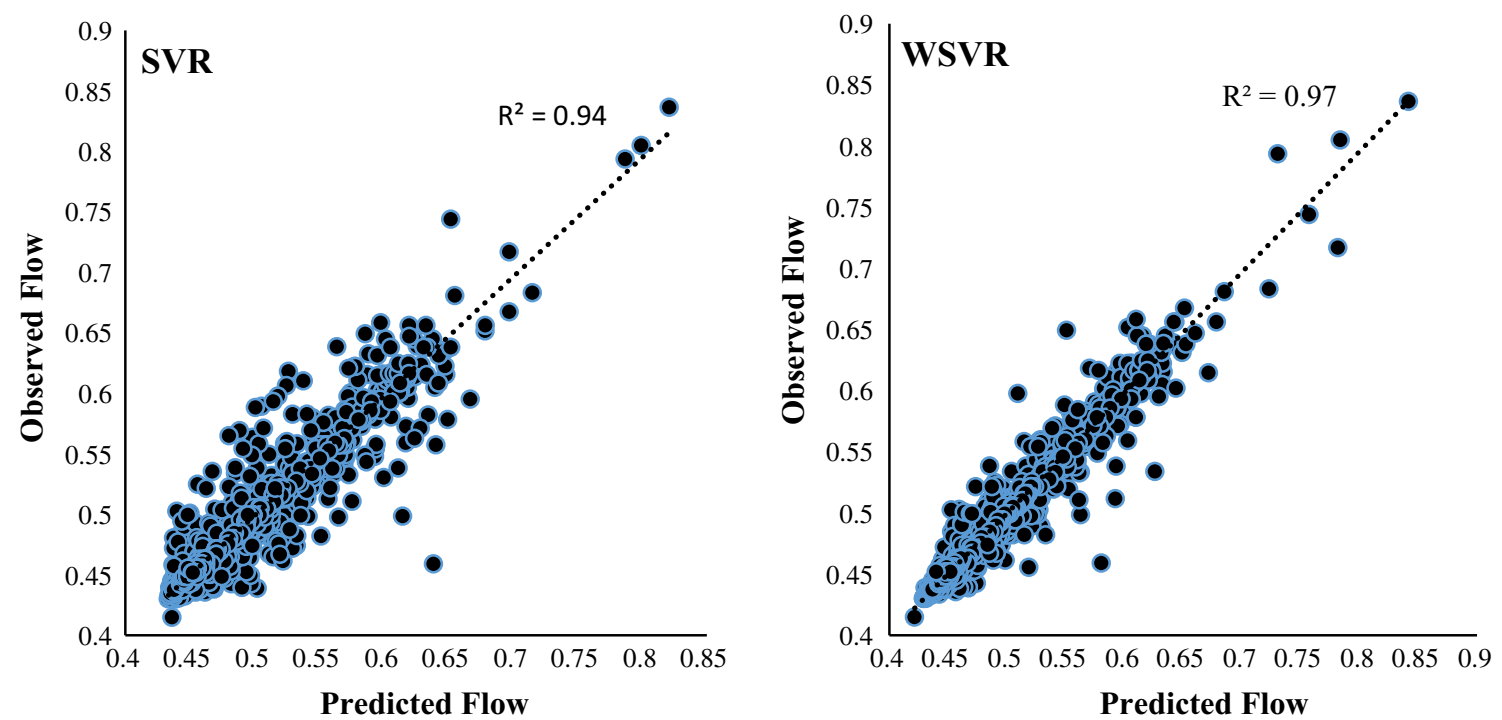

Figure 6. The predicted flow vs. observed flow for the used models in daily period.
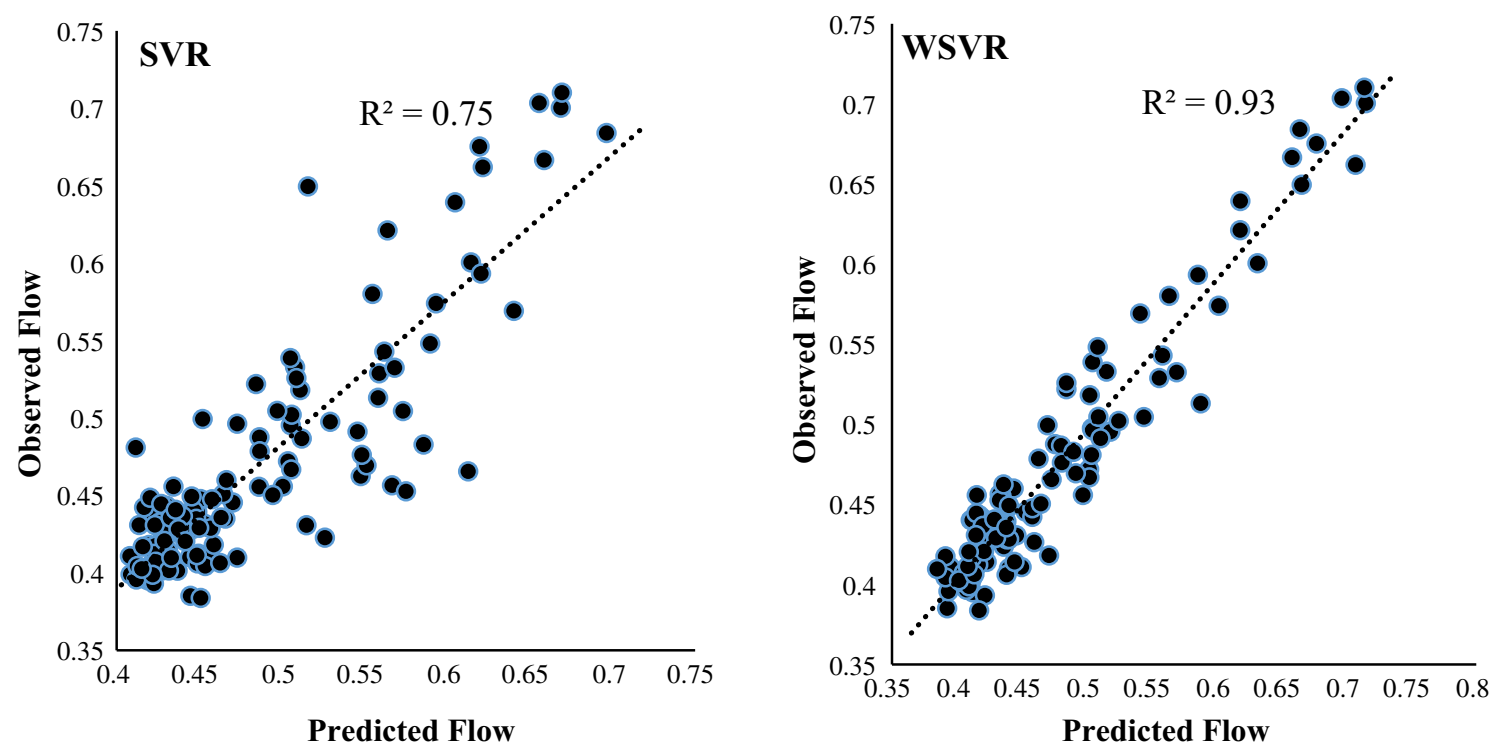

Figure 7. The predicted flow vs. observed flow for the used models in monthly period.

By solving equations (11 and 12), the eigenvalues and eigenvectors corresponding to each eigenvalue are calculated. The eigenvectors obtained for each eigenvalue are also the coefficients of primary variables in forming the corresponding components.

By solving equation (11) where $I$ is the identity matrix, the eigenvalues of $\lambda_{n}$ are calculated.

$$
\operatorname{det}(R-\lambda I)=0
$$

The variance value of each main component is calculated by equation (12).

$$
\operatorname{det}(R-\lambda I)=V_{h}
$$

- The criteria to extract the components: Eigenvalue, variance percentage and the cut test criteria are the main parameters to extract the number of factors which is applied in this process (Cattel 1996).

- Implementation of proper rotation on the matrix of the components coefficient: this stage is also known as the principal factor analysis. In this stage, the variables which have a high coefficient in the main extracted component are selected as the main variables for modeling (Singh et al. 2004). 
Table 8. Result of the WGEP daily with different mother wavelets and decomposition levels.

\begin{tabular}{|c|c|c|c|c|c|}
\hline \multirow{2}{*}{$\begin{array}{l}\text { Mother } \\
\text { wavelet type }\end{array}$} & \multirow{2}{*}{$\begin{array}{c}\text { Decomposition } \\
\text { level }\end{array}$} & \multicolumn{2}{|c|}{$\mathrm{R}^{2}$} & \multicolumn{2}{|c|}{ RMSE } \\
\hline & & Train & Test & Train & Test \\
\hline Coif1 & 5 & 0.96 & 0.94 & 0.0110 & 0.0111 \\
\hline Coif1 & 6 & 0.96 & 0.94 & 0.0109 & 0.0112 \\
\hline Coif1 & 7 & 0.93 & 0.88 & 0.0145 & 0.0157 \\
\hline Coif1 & 8 & 0.94 & 0.92 & 0.0133 & 0.0125 \\
\hline Coif1 & 9 & 0.94 & 0.92 & 0.0137 & 0.0128 \\
\hline Sym3 & 5 & 0.96 & 0.95 & 0.0107 & 0.0105 \\
\hline Sym3 & 6 & 0.97 & 0.95 & 0.0102 & 0.0105 \\
\hline Sym3 & 7 & 0.95 & 0.92 & 0.0124 & 0.0125 \\
\hline Sym3 & 8 & 0.98 & 0.96 & 0.0081 & 0.0088 \\
\hline Sym3 & 9 & 0.92 & 0.88 & 0.0158 & 0.0156 \\
\hline Haar & 5 & 0.96 & 0.93 & 0.0109 & 0.0120 \\
\hline Haar & 6 & 0.96 & 0.93 & 0.0117 & 0.0121 \\
\hline Haar & 7 & 0.93 & 0.89 & 0.0150 & 0.0151 \\
\hline Haar & 8 & 0.97 & 0.94 & 0.0101 & 0.0115 \\
\hline Haar & 9 & 0.91 & 0.86 & 0.0173 & 0.0166 \\
\hline Db2 & 5 & 0.96 & 0.95 & 0.0110 & 0.0103 \\
\hline Db2 & 6 & 0.97 & 0.95 & 0.0103 & 0.0103 \\
\hline Db2 & 7 & 0.94 & 0.91 & 0.0135 & 0.0134 \\
\hline Db2 & 8 & 0.97 & 0.95 & 0.0101 & 0.0101 \\
\hline Db2 & 9 & 0.95 & 0.94 & 0.0120 & 0.0113 \\
\hline $\mathrm{Db} 4$ & 5 & 0.96 & 0.94 & 0.0106 & 0.0109 \\
\hline $\mathrm{Db} 4$ & 6 & 0.97 & 0.94 & 0.0104 & 0.0109 \\
\hline $\mathrm{Db} 4$ & 7 & 0.98 & 0.96 & 0.0073 & 0.0095 \\
\hline $\mathrm{Db} 4$ & 8 & 0.94 & 0.91 & 0.0141 & 0.0145 \\
\hline $\mathrm{Db} 4$ & 9 & 0.96 & 0.94 & 0.0108 & 0.0111 \\
\hline
\end{tabular}

\subsection{Hybrid models}

At first, every input parameters were converted to sub-signals using wavelet transform. Then the subsignals produced were detected using the PCA, and important factors as inputs were entered to the SVR and GEP to produce the WGEP and WSVR.

Figure 3 shows the schematic diagram of the WGEP. In this figure, sub-signals $\mathrm{Pa}(\mathrm{t}), \mathrm{Ta}(\mathrm{t})$, $\mathrm{Q}_{\mathrm{a}}(\mathrm{t}), \mathrm{E}_{\mathrm{a}}(\mathrm{t})$ are related to the overall scale (approximate) of the final level, and the other sub-signals are related to the small scale (detail) of level 1 to the final level.

\section{Model evaluation criteria}

For evaluating the performance of models in prediction results, different qualitative and quantitative parameters have to be detected to clear the effect of every input parameter on the results. So, $R^{2}$, RMSE, AIC, and OI were used for evaluating the performance of models.

$$
\begin{aligned}
\mathrm{RMSE}= & \sqrt{\frac{\sum\left(Q_{\mathrm{obs}}-Q_{\mathrm{pre}}\right)^{2}}{n}} \\
R^{2}= & 1-\frac{\sum_{i=1}^{N}\left(Q_{\mathrm{obs}}-Q_{\mathrm{pre}}\right)^{2}}{\sum_{i=1}^{N}\left(Q_{\mathrm{obs}}-\bar{Q}\right)^{2}} \\
\mathrm{AIC}= & m \times \ln (\mathrm{RMSE})+2(\mathrm{Npar}) \\
\mathrm{OI}= & \frac{1}{2}\left(2-\frac{\mathrm{RMSE}}{Q_{\max }-Q_{\mathrm{min}}}\right. \\
& \left.+\frac{\sum_{i=1}^{N}\left(Q_{\mathrm{obs}}-Q_{\mathrm{pre}}\right)^{2}}{\sum_{i=1}^{N}\left(Q_{\mathrm{obs}}-\bar{Q}\right)^{2}}\right)
\end{aligned}
$$

In these equations, $Q$ is the observed flow, $Q_{\text {pre }}$ is the predicted flow and $\bar{Q}$ is the mean flow. RMSE (root-mean-square error) shows the difference between two groups. $R^{2}$ (coefficient of determination) explains the probability of a direct correlation between two groups. Actually, it shows how much the predicted data are matched. AIC (Akaike Information Criterion) is a criterion for evaluating the goodness-of-fit. This criterion shows how much information is missed by using a model. 
Table 9. Result of the WGEP monthly with different mother wavelets and decomposition levels.

\begin{tabular}{|c|c|c|c|c|c|}
\hline \multirow{2}{*}{$\begin{array}{c}\text { Mother } \\
\text { wavelet type }\end{array}$} & \multirow{2}{*}{$\begin{array}{c}\text { Decomposition } \\
\text { level }\end{array}$} & \multicolumn{2}{|c|}{$R^{2}$} & \multicolumn{2}{|c|}{ RMSE } \\
\hline & & Train & Test & Train & Test \\
\hline Coif1 & 1 & 0.93 & 0.65 & 0.0260 & 0.0452 \\
\hline Coif1 & 2 & 0.93 & 0.70 & 0.0258 & 0.0423 \\
\hline Coif1 & 3 & 0.93 & 0.76 & 0.0259 & 0.0373 \\
\hline Coif1 & 4 & 0.92 & 0.68 & 0.0286 & 0.0432 \\
\hline Sym3 & 1 & 0.87 & 0.74 & 0.0357 & 0.0391 \\
\hline Sym3 & 2 & 0.96 & 0.82 & 0.0196 & 0.0336 \\
\hline Sym3 & 3 & 0.93 & 0.83 & 0.0259 & 0.0317 \\
\hline Sym3 & 4 & 0.91 & 0.77 & 0.0298 & 0.0376 \\
\hline Haar & 1 & 0.90 & 0.58 & 0.0302 & 0.0521 \\
\hline Haar & 2 & 0.90 & 0.73 & 0.0302 & 0.0393 \\
\hline Haar & 3 & 0.90 & 0.65 & 0.0303 & 0.0450 \\
\hline Haar & 4 & 0.92 & 0.75 & 0.0279 & 0.0380 \\
\hline Db2 & 1 & 0.96 & 0.70 & 0.0192 & 0.0448 \\
\hline Db2 & 2 & 0.93 & 0.60 & 0.0258 & 0.0505 \\
\hline Db2 & 3 & 0.93 & 0.70 & 0.0259 & 0.0452 \\
\hline Db2 & 4 & 0.90 & 0.73 & 0.0303 & 0.0396 \\
\hline Db4 & 1 & 0.94 & 0.85 & 0.0249 & 0.0296 \\
\hline Db4 & 2 & 0.96 & 0.87 & 0.0191 & 0.0278 \\
\hline $\mathrm{Db} 4$ & 3 & 0.96 & 0.78 & 0.0192 & 0.0356 \\
\hline Db4 & 4 & 0.95 & 0.79 & 0.0228 & 0.0358 \\
\hline
\end{tabular}

OI shows the overall performance index and RMSE is part of this index. OI is between $-\infty$ and 1 . If the RMSE decrease, OI leads to 1 and show more accurate prediction (Mattar and Alamoud 2015).

\section{Results and discussions}

\subsection{Results of the SVR and GEP model}

For running the SVR, different structures were determined for every detected combination. Table 3 shows the best structures with their results for both daily and monthly scales. According to this table, it can be seen that for both daily and monthly scales, combination 5 is better than others. It means using temperature and evaporation data, in addition to precipitation and river flow, improves the function of the model. For the daily period, $R^{2}=0.94$, RMSE $=0.0109$, and $\mathrm{RBF}$ kernel had the best function. For the monthly period, $R^{2}=0.75, \mathrm{RMSE}=0.0413$, and with one lag time had the best function. Also, according to the table and the comparison between combination 5 and 6 , it was cleared that the increase of the steps of time, more than one step, has an inverse result and decrease the function of the model.
For running the GEP, different structures were detected for every combination. Table 4 shows the best structures with their results in daily and monthly scales. According to this table, it is cleared that in both daily and monthly scales, combination 5 is better than other combination. It means using temperature and evaporation data, in addition to precipitation and flow data, increases the performance of models. According to the table, it was cleared that the performance of model in daily scale $\left(R^{2}=0.92\right)$ is really better than monthly scale $\left(R^{2}=0.64\right)$. The result of RMSE proves this conclusion.

\subsection{Results of hybrid model}

For monthly scale, based on Nourani et al. (2009a, b), $L$ was used for determining the degree of the decomposition (Nourani et al. 2009a, b).

$$
L=\operatorname{Int}[\log (N)]
$$

In this equation, $L$ is the level of suggested decomposition and $N$ is the number of time series. In this study, $L=2$ is calculated with 516 data and for more accuracy, $L=1$ to 4 were detected as well. In addition, for daily scale, $L=5$ to 9 were 

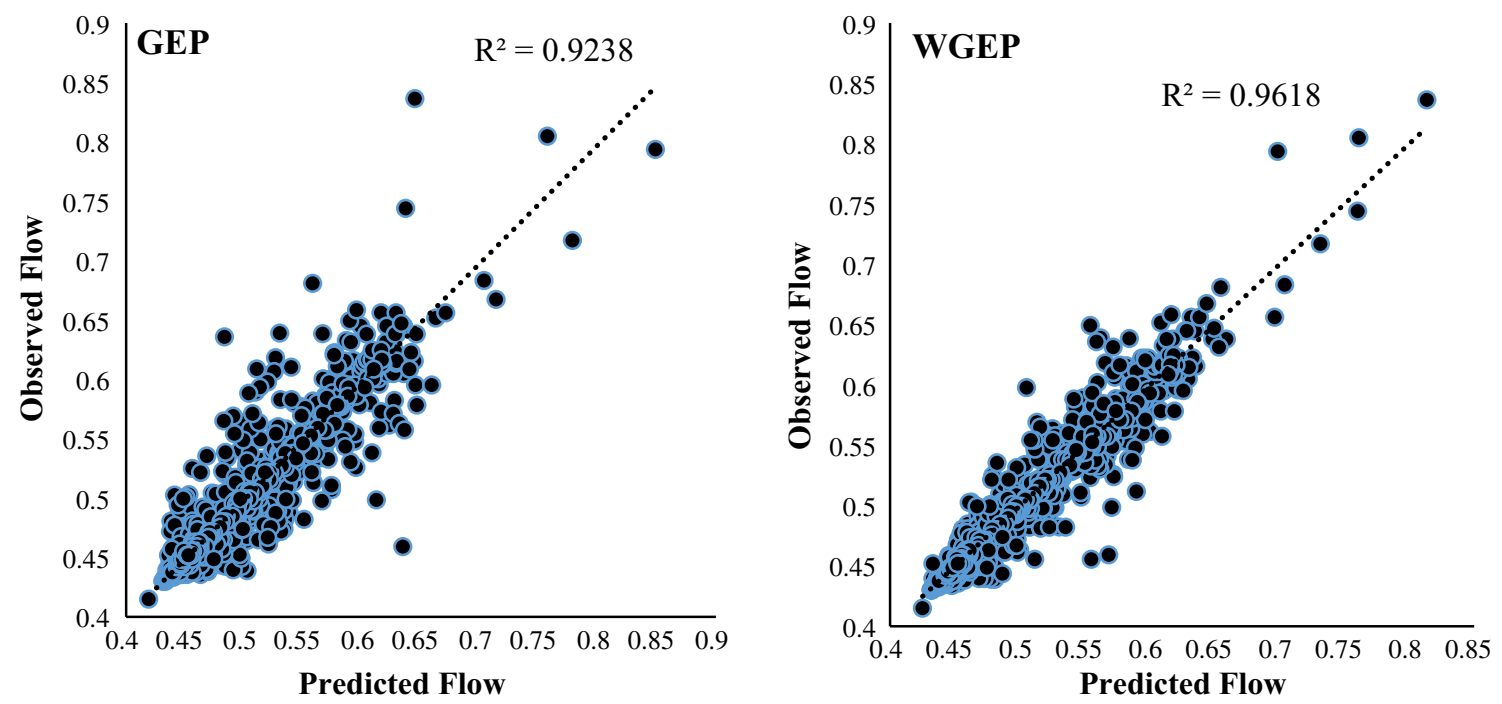

Figure 8. The predicted flow vs. observed flow for the used models in daily period.
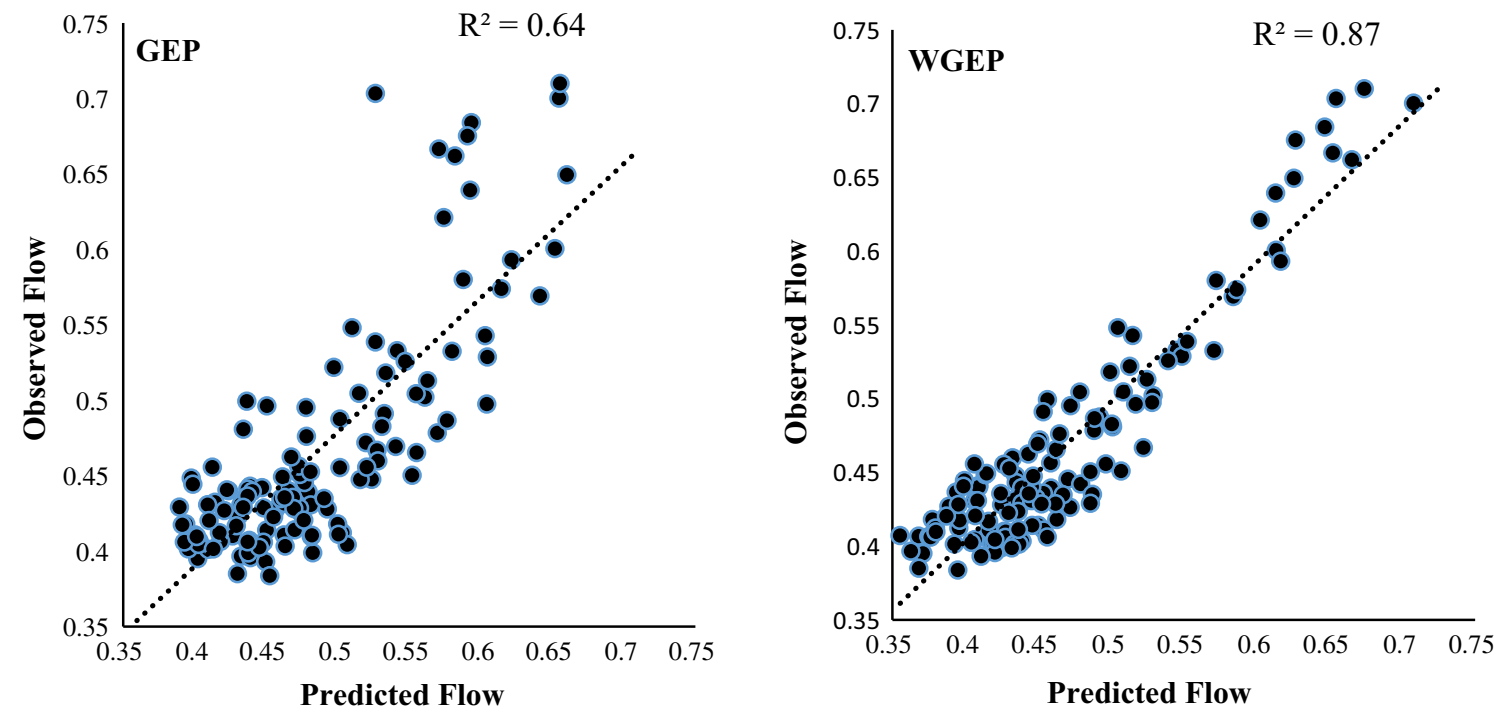

Figure 9. The predicted flow vs. observed flow for the used models in monthly period.

used. Because decomposing main signals with different $L$ takes too much time, produce too many sub-signals, decrease the function of model, and increase the time for running, PCA was used and important sub-signals and inputs were entered to the SVR and GEP to produce the WSVR and WGEP.

\subsection{Results of PCA method}

After using wavelet transform, important subsignals were selected using the PCA due to too many different sub-signals based on wavelet transform and $L$. Regarding $\mathrm{KMO}=0.607$ (table 5), using PCA is verifiable. For running PCA, after standardizing inputs, symmetric correlation matrix $R$ ranked 40, equal to the maximum number of daily inputs, was established. Then, 40 special amounts and for every special amount, 40 eigenvectors were produced and by using them 40 components, equal to variable inputs, were produced. According to figure 4, for daily scale, the first 20 components show $95 \%$ dispersion and the information of main variables from the 40 input components, while the first 12 components show $89 \%$ dispersion and the information of main variables. Therefore, the first 20 components were used for daily scale. 
Table 10. Comparison the models used in this study.

\begin{tabular}{|c|c|c|c|c|c|c|c|c|c|}
\hline \multirow{2}{*}{$\begin{array}{l}\text { Model } \\
\text { type }\end{array}$} & \multirow{2}{*}{$\begin{array}{l}\text { Time } \\
\text { scale }\end{array}$} & \multicolumn{2}{|c|}{$R^{2}$} & \multicolumn{2}{|c|}{ RMSE } & \multicolumn{2}{|c|}{ AIC } & \multicolumn{2}{|c|}{ OI } \\
\hline & & Train & Test & Train & Test & Train & Test & Train & Test \\
\hline \multirow{2}{*}{ SVR } & Daily & 0.950 & 0.941 & 0.0127 & 0.0109 & 23538.53 & 7833.93 & 0.962 & 0.958 \\
\hline & Monthly & 0.884 & 0.749 & 0.0339 & 0.0413 & 758.46 & 243.25 & 0.906 & 0.788 \\
\hline \multirow{2}{*}{ GEP } & Daily & 0.948 & 0.924 & 0.0129 & 0.0125 & 23538.61 & 7834.47 & 0.961 & 0.946 \\
\hline & Monthly & 0.805 & 0.635 & 0.0433 & 0.0503 & 759.44 & 244.04 & 0.858 & 0.703 \\
\hline \multirow{2}{*}{ WSVR } & Daily & 0.980 & 0.971 & 0.0079 & 0.0077 & 23439.82 & 7735.15 & 0.982 & 0.976 \\
\hline & Monthly & 0.951 & 0.930 & 0.0217 & 0.0207 & 726.03 & 239.46 & 0.953 & 0.931 \\
\hline \multirow{2}{*}{ WGEP } & Daily & 0.979 & 0.962 & 0.0081 & 0.0088 & 23536.74 & 7833.06 & 0.944 & 0.916 \\
\hline & Monthly & 0.963 & 0.868 & 0.0191 & 0.0278 & 756.17 & 241.67 & 0.962 & 0.890 \\
\hline
\end{tabular}

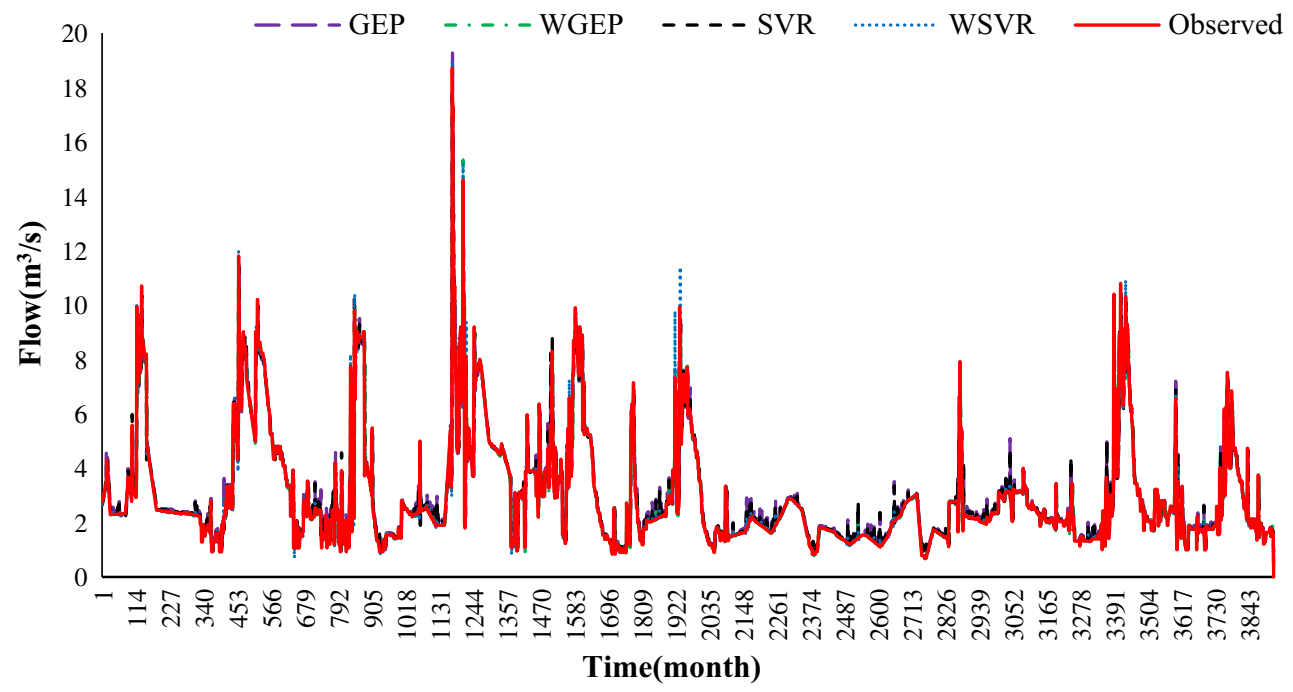

Figure 10. Comparison of the models used in this study in the daily period.

In the monthly period, as it can be seen, forming the first component includes more than $62 \%$ information of the primary variables. Also, the table shows that the first 12 components show about $99 \%$ whole distribution and the information of main variables, while the first 8 components show $95 \%$ distribution and the information of main variables. Therefore, it was decided to use the first 12 components for monthly scale. Figure 5 shows both eigenvalues and percentage variances as a graph which supports the above results.

The results of detection of different WSVR structures for every parameter for daily scale are shown in table 6 and for monthly scale in table 7 .

According to table $6, \mathrm{Db} 4$ in $L=5$ has the best function. The structure has RBF kernel with $R^{2}=0.97$ and RMSE $=0.0075$. Also, according to table 7, for monthly scale, Db4 with $L=2$, for RBF kernel, $R^{2}=0.92$, and simulated $\mathrm{RMSE}=0.0219$ has the best function.
Figures 6 and 7 show the estimated values with different models vs. observed data in daily and monthly scales.

Regarding figure 6, the comparison between SVR and WSVR shows the better function in combined models. In figure 7, the function of every model $v s$. observed data has been depicted. In these figures, graphs are based on monthly scale and standardized values. By comparing the SVR and WSVR, it can be concluded that the determination coefficient of the function of combined models in monthly scale has decreased in comparision with daily scale.

The comparison of WSVR and SVR shows that combined models are better and the function of the SVR increased by $19 \%$ because of combining wavelet transform. Therefore, it can be concluded that wavelet transform increases the determination coefficient in monthly scale clearly.

The result of evaluation of different WGEP structures for every wavelet function in different 


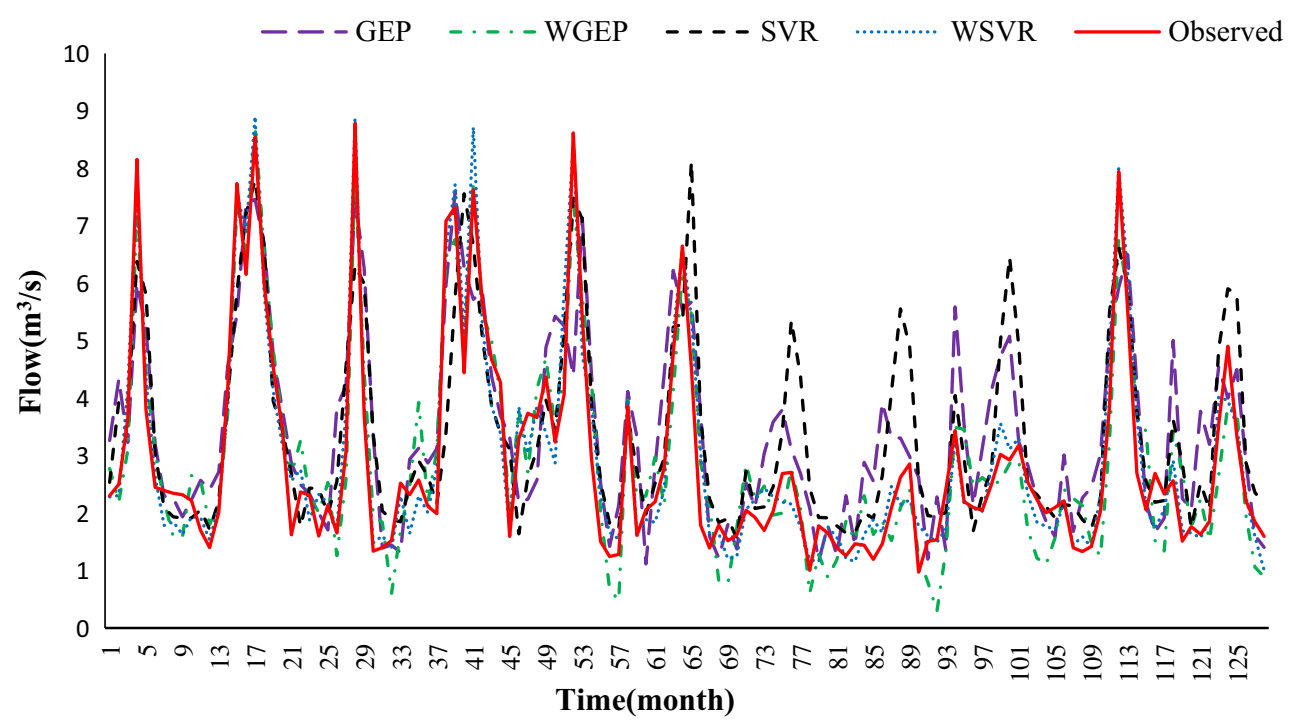

Figure 11. Comparison of the models used in this study in the monthly period.

decomposition levels for daily scale are presented in table 8 and for monthly scale are presented in table 9 .

According to table 8, Sym3 wavelet function in $L=3$ has the best performance. This structure has $R^{2}=0.96$ and $\mathrm{RMSE}=0.0088$. Also, according to table 9, Db4 wavelet function in $L=2$ has the best performance in monthly scale. This structure has $R^{2}=0.96$ and $\mathrm{RMSE}=0.0278$. Figures 8 and 9 show the obtained values for different models vs. observed values for daily and monthly scales.

According to figure 8 and $R^{2}$ of GEP in daily scale, it is clear that the performance of the model has been good. The comparison between the GEP and WGEP showed that WGEP model was better. It means the use of wavelet model increases the performance of GEP model. In figure 9, the performance of every model vs. observed values has been depicted. In these figures, graphs are based on monthly scale and standardized values. By comparing the $R^{2}$ of GEP in daily and monthly scales, it can be indicated that the performance of the model in daily scale has decreased.

By comparing the WGEP with GEP, it is proved that the WGEP had better performance and the performance increases up to $23 \%$. It is because of wavelet transform and a pre-process which has been done on data. Table 10 shows the comparison of models in daily and monthly scales based on $R^{2}$, RMSE, and AIC.

According to the table and based on $R^{2}$, WSVR in daily and monthly scales has the best function with $R^{2}=0.97$ and 0.93 , respectively. WSVR has the minimum RMSE in daily and monthly scales and is the best model. According to AIC, WSVR is the best model for both scales as well. Also, the OI index proved that in the daily and monthly scales, the performance of WSVR was better than other models (it is near to 1 ).

Figures 10 and 11 show the comparison among different models for daily and monthly scales.

According to figure 8, the performance of models is the same approximately due to having many data, but the WSVR has closer values to observed values. According to figure 9, the comparison among models in the monthly scale, having fewer data, have more clear difference and the good function of combined model can be proved to estimate minimum and maximum values. In addition, the result of this study is consistent with the study of Kisi and Cimen (2012) which showed the good function of hybrids for predicting precipitation and announced the use of wavelet transform to increase the performance of models. Also, the results of this study, like the study of Shoaib et al. (2015) and Karimi et al. (2015), show the better performance of WGEP than the GEP for predicting river flow.

\section{Conclusion}

In this study, river flow of Gamasiyab River, located in Nahavand, Iran, was modeled and predicted using the GEP and SVR in daily and monthly scales. The results showed that the performance of both the GEP and SVR in daily scale 
was suitable, with $R^{2}=0.92$ and 0.94 respectively, but in the monthly scale, the performance of models had a considerable decrease, with $R^{2}=0.64$ and 0.75 respectively. Therefore, at the next step, the wavelet transform and PCA method were used to increase the accuracy and the speed of running models. By using the wavelet transform, sub-signals were generated and by using the PCA method, important sub-signals were recognized and were used as inputs for the GEP and SVR to produce the WGEP and WSVR (hybrid models). The results showed that using these techniques improve the function of the models in both of daily and monthly scales. In the daily scale, the performance increased by $3-4 \%$ (it is not a significant change because there were a lot of data on this scale). In the monthly scale, the performance increased by $18-23 \%$ which was considerable. Finally, the WSVR and WGEP were compared and it was cleared that the WSVR had better performance than the WGEP. In the daily scale, $R^{2}$ was 0.971 for the WSVR and for the WGEP, $R^{2}$ was 0.962 . Also, in the monthly scale, $R^{2}$ was 0.930 for the WSVR and for the WGEP, $R^{2}$ was 0.868. Totally, it can be said that the combination of SVR with wavelet transform was a proper tool for simulating and predicting the river flow of Gamasiyab River.

\section{Acknowledgement}

This study has been supported by the minister of Regional Water of Hamedan by providing necessary data and information.

\section{References}

Adamowski J and Sun K 2010 Development of a coupled wavelet transform and neural network method for flow forecasting of non-perennial rivers in semi-arid watersheds; J Hydrol. 390 85-91.

Asadi S, Shahrabi J, Abbaszadeh P and Tabanmehr S 2013 A new hybrid artificial neural networks for rainfall-runoff process modeling; Neurocomputing 121 470-480.

Belayneh A, Adamowski J, Khalil B and Ozga-Zielinski B 2014 Long-term SPI drought forecasting in the Awash River Basin in Ethiopia using wavelet neural network and wavelet support vector regression models; J. Hydrol. 508 418-429.

Belayneh A, Adamowski J, Khalil B and Quilty J 2016 Coupling machine learning methods with wavelet transforms and the bootstrap and boosting ensemble approaches for drought prediction; Atmos. Res. 172-173 37-47.
Caliendo C and Parisi A 2005 Principal component analysis applied to crash data on multilane roads; Third International SIIV Congress, Bari, Italy, ANCONA SIIV. 1 $1-7$.

Cattel R B 1996 The scree test for the number of factors; Multivariate Behav. Res. 1(2) 245-276.

Cortes C and Vapnik V 1995 Support-vector networks; Mach. Learn. 20(3) 273-295.

Danandeh Mehr A, Kahya E and Özger M 2014 A genewavelet model for long lead time drought forecasting; $J$. Hydrol. 517 691-699.

Danandeh Mehr A and Majdzadeh Tabatabai M R 2010 Prediction of daily discharge trend of river flow based on genetic programming; J. Water Soil (Iran) 24(2) 325333.

Dorum A, Yarar A, Faik Sevimli M and Onüçyildiz M 2010 Modelling the rainfall-runoff data of Susurluk basin; Expert Syst. Appl. 37(9) 6587-6593.

Ferreira C 2001 Gene expression programming: A new adaptive algorithm for solving problems; Complex Syst. 13 $87-129$.

Ferreira C 2006 Gene Expression Programming: Mathematical Modeling by an Artificial Intelligence (Studies in Computational Intelligence); Springer-Verlag New York, Inc. Secaucus, NJ, USA.

Hamzaçebi C 2008 Improving artificial neural networks' performance in seasonal time series forecasting; Inf. Sci. (Ny). 178(23) 4550-4559.

He Z, Wen X, Liu H and Du J 2014 A comparative study of artificial neural network, adaptive neuro fuzzy inference system and support vector machine for forecasting river flow in the semiarid mountain region; J. Hydrol. 509379 386.

Hutcheson G and Nick S 1999 The multivariate social scientist: Introductory statistics using generalized linear models; Thousand Oaks, CA, Sage Publications, 278p.

Johnson R A and Wichern D W 1982 Applied multivariate statistical analysis (6th edn); Englewood Cliffs, SA.

Karimi S, Shiri J, Kisi O and Shiri A A 2015 Short-term and long-term streamflow prediction by using 'wavelet-gene expression' programming approach; ISH J. Hydrol. Eng. 22(2) 148-162.

Kisi O 2008 Stream flow forecasting using neuro-wavelet technique; Hydrol. Process. 22 4142-4152.

Kisi O and Cimen M 2012 Precipitation forecasting by using wavelet-support vector machine conjunction model; Eng. Appl. Artif. Intell. 25(4) 783-792.

Kisi O, Shiri J and Nazemi A H 2011 A wavelet-genetic programming model for predicting short-term and long-term air temperatures; J. Civil Eng. Urban. 1(1) 25-37.

Foufoula-Georgiou E and Kumar P 1994 Wavelet in Geophysics: An Introduction; Academic Press, San Diego New York Boston, London, Sydney, Tokyo, Toronto, 373p.

Mallat S 1998 A wavelet tour of signal processing; The Sparse Way, San Diego.

Mattar M A and Alamoud A I 2015 Artificial neural networks for estimating the hydraulic performance of labyrinthchannel emitters; Comput. Electron. Agric. 114(5) 189201.

Nakken M 1999 Wavelet analysis of rainfall-runoff variability isolating climatic from anthropogenic patterns; Environ. Model Softw. 14(4) 283-295. 
Nayak P C, Sudheer K P, Rangan D M and Ramasastri K S 2004 A neuro-fuzzy computing technique for modeling hydrological time series; J. Hydrol. 291(1-2) 52-66.

Nourani V, Alami M T and Aminfar M H 2009 A combined neural-wavelet model for prediction of Ligvanchai watershed precipitation; Eng. Appl. Artif. Intell. 22(3) 466-472.

Nourani V and Komasi M 2013 A geomorphology-based ANFIS model for multi-station modeling of rainfall-runoff process; J. Hydrol. 490 41-55.

Nourani V, Komasi M and Mano A 2009 A multivariate ANN-wavelet approach for rainfall-runoff modeling; Water Resour. Manag. 23 2877-2894.

Piotrowski A P and Napiorkowski J J 2013 A comparison of methods to avoid overfitting in neural networks training in the case of catchment runoff modelling; J. Hydrol. 476 97-111.

Pramanik N and Panda R K 2009 Application of neural network and adaptive neurofuzzy inference systems for river flow prediction; J. Hydrol Sci. 54(2) 247-260.

Riad S, Mania J, Bouchaou L and Najjar Y 2004 Rainfallrunoff model using an artificial neural network approach; Math Comput. Model. 40(7-8) 839-846.

Shiri J and Kişi Ö 2011 Comparison of genetic programming with neuro-fuzzy systems for predicting short-term water table depth fluctuations; Comput. Geosci. 37(10) 16921701.

Shiri J, Kişi Ö, Landeras G, López J J, Nazemi A H and Stuyt L C P M 2012 Daily reference evapotranspiration modeling by using genetic programming approach in the Basque Country (Northern Spain); J. Hydrol. 414-415 302-316.

Shoaib M, Shamseldin A Y and Melville B W 2014 Comparative study of different wavelet based neural network models for rainfall-runoff modelling; J. Hydrol. 515 47-58.

Shoaib M, Shamseldin A Y, Melville B W and Khan M M 2015 Runoff forecasting using hybrid wavelet gene expression programming (WGEP) approach; J. Hydrol. $527326-344$.

Singh K P, Malik A, Mohan D and Sinha S 2004 Multivariate statistical techniques for the evaluation of spatial and temporal variations in water quality of Gomti River (India): A case study; Water Res. 38(18) 3980-3992.

Solgi A 2014 Stream flow forecasting using combined neural network wavelet model and comparsion with adaptive neuro fuzzy inference system and artificial neural network methods (Case study: Gamasyab River, Nahavand); MSc. Persian, Shahid Chamran University of Ahvaz, Iran.

Solgi A, Radmanesh F, Pourhaghi A and Bagherian Marzouni M 2014a Evaluation of artificial intelligence systems performance in precipitation forecasting; J. Agric. Sci. Dev. 3(7) 256-264.

Solgi A, Nourani V and Pourhaghi A 2014b Forecasting daily precipitation using hybrid model of wavelet-artificial neural network and comparison with adaptive neuro fuzzy inference system (Case study: Varayneh Station, Nahavand); Adv. Civ. Eng. 2014 1-12.

Sujay Raghavendra N and Deka P C 2014 Support vector machine applications in the field of hydrology: A review; Appl. Soft Comput. 19 372-386.

Suryanarayana C, Sudheer C, Mahammood V and Panigrahi B K 2014 An integrated wavelet-support vector machine for groundwater level prediction in Visakhapatnam, India; Neurocomputing 145 324-335.

Talei A, Chua L H C and Quek C 2010 A novel application of a neuro-fuzzy computational technique in eventbased rainfall-runoff modeling; Expert Syst. Appl. 37(12) 7456-7468.

Wu C L and Chau K W 2011 Rainfall-runoff modeling using artificial neural network coupled with singular spectrum analysis; J. Hydrol. 399(3-4) 394-409.

Wu C L, Chau K W and Li Y S 2009 Methods to improve neural network performance in daily flows prediction; J. Hydrol. 372(1-4) 80-93. 